\title{
3D velocity field time series using synthetic aperture radar: application to tidal-timescale ice-flow variability in Rutford Ice Stream, West Antarctica
}

\author{
Pietro Milillo ${ }^{1,2}$, Brent Minchew $^{3}$, Piyush Agram ${ }^{1}$, Bryan Riel $^{4}$ and Mark Simons ${ }^{4}$ \\ ${ }^{1}$ NASA Jet Propulsion Laboratory, California Institute of Technology, 4800 Oak Grove Drive, \\ 91109 Pasadena (CA), USA. \\ ${ }^{2}$ School of Engineering, University of Basilicata, Potenza, Italy \\ ${ }^{3}$ British Antarctic Survey, High Cross Madingley Road CAMBRIDGE CB3 0ET, UK \\ ${ }^{4}$ Seismological Laboratory, California Institute of Technology, Pasadena, CA 91125, USA
}

\begin{abstract}
We present a general method for retrieving time-series of three component surface velocity field vector given a set of continuous synthetic aperture radar (SAR) acquisitions collected from multiple geometries. Our algorithm extends the single-line-of-sight mathematical framework developed for time-series analysis using interferometric SAR (InSAR) to three spatial dimensions. The inversion is driven by a design matrix corresponding to a dictionary of displacement functions parameterized in time. The resulting model minimizes a cost function using a non-regularized least-squares method. We applied our method to Rutford ice stream (RIS), West Antarctica, using a set of 101 multi-track multiangle COSMO-SkyMed displacement maps generating azimuth and range pixel offsets.
\end{abstract}

Keywords: 3D analysis, ocean tides, pixel offsets, Rutford Ice Stream, SAR, time-series analysis.

\section{INTRODUCTION}

In the last 25 years Synthetic Aperture Radar (SAR) based geodetic measurements such as interferometric SAR (InSAR) and pixel offsets (PO) became a widely used tool for monitoring geophysical and anthropogenic phenomena $[1,2]$. Series of InSAR and PO deformation maps are usually combined in time-series of deformation $[3,4]$ representing the projection of the 3D displacement vector across-track (onto the sensor line-of-sight (LOS) direction) for InSAR and PO (in the range direction) or along-track for PO (in the azimuth direction) and multiple aperture interferometry (MAI) measurement.

The increase in available SAR data from multiple sensors combined with the ability to monitor the Earth's land surface with decreasing revisit time provides the potential to analyze a variety of short timescale natural and anthropogenic processes that were previously inaccessible [5,9]. In some cases, these capabilities requires one to extend single-LOS methods to two or three spatial components [10]. Several approaches merge combinations of datasets from ascending and descending orbits combining InSAR with PO or MAI observations in order to reconstruct the complete 3 component vectors [11-27].

SAR Image Analysis, Modeling, and Techniques XVI, edited by Claudia Notarnicola, Simonetta Paloscia,

Nazzareno Pierdicca, Edward Mitchard, Proc. of SPIE Vol. 10003, 1000309 · C 2016 SPIE

CCC code: $0277-786 X / 16 / \$ 18 \cdot$ doi: $10.1117 / 12.2241617$ 
Here we present a method for inferring time-dependent 3D surface velocity fields from a suite of synthetic aperture radar (SAR) acquisitions collected from multiple geometries at different times. Our algorithm extends the single line-of-sight framework developed for time-series analysis using interferometric SAR (InSAR) to three spatial dimensions. The inversion relies on a dictionary of temporal displacement functions. The resulting model minimizes a cost function using a non-regularized least-squares method. We applied our method to RIS using a set of 101 multi-track, multi-angle COSMO-SkyMed (CSK) observations of azimuth and range pixel offsets. We focus on the special case where surface velocities can be represented by a 3D secular velocity and a family of sinusoidal functions whose periods are known a priori from GPS observations. SAR measurements provide coverage of ground deformation at spatial scales not reasonably accessible with in situ measurements such as GPS. SAR satellites are also capable of acquiring data in remote areas where optical sensors may be ineffective due to darkness or atmospheric conditions. Constellations, such as CSK, provide a reduced revisit time and high spatial resolution (up to $1 \mathrm{~m}$ ), leading to high measurements accuracy and tight constraints on fast moving processes such as ice streams. Due to decreasing repeat acquisition intervals and reduced latency in data availability, SAR techniques are now beginning to provide effective short-term monitoring that will improve the understanding of the evolution of glaciers and ice sheets and address several key issues, including:

I. How grounding zones migrate on timescales characteristic of ocean tides and what role does any migration play in ice-stream-scale flow [28-31].

II. How stresses are transmitted over long distances (tens of $\mathrm{km}$ ) upstream of the grounding line on hourly timescales [32].

III. What are the roles of variations in basal water pressure and subglacial till rheology on ice-stream-scale flow [33]

\section{METHODS}

The algorithm is based on a mathematical scheme already developed for multi-scale InSAR time series analysis [34] in the single LOS domain using either pixel-by-pixel or wavelet decompositions in the space domain. We consider a set of $N$ images acquired at times $\left(t_{1} t_{n}\right)$ combined in $M$ displacement maps. We assume a pixel offsets measurement is available both in range and azimuth directions for every displacement map. Given the physical nature of the observed deformation [33,35] we consider only a secular velocity augmented by a set of $\mathrm{k}$ sinusoidal functions. A single pixel offset map over timespan $\Delta t_{i, j}=t_{j}-t_{i}$ can be written as:

$$
\Lambda_{i, j}=\psi_{i, j} \hat{\boldsymbol{l}} \cdot\left(\boldsymbol{s} \frac{\Delta t_{i j}}{\tau}+\sum_{p=1}^{k}\left[\mathbf{S}_{p}\left(t_{j}\right)-\mathbf{S}_{p}\left(t_{i}\right)+\mathbf{C}_{p}\left(t_{j}\right)-\mathbf{C}_{p}\left(t_{i}\right)\right]\right)
$$

where the incidence-like matrix is given as:

$$
\psi_{i, j}=\left\{\begin{array}{c}
1 \forall i>j \wedge \Lambda_{i, j} \in \boldsymbol{D} \\
-1 \forall i<j \wedge \Lambda_{i, j} \in \boldsymbol{D} \\
0 \text { elsewhere }
\end{array}\right.
$$

Here, $\boldsymbol{D}$ is a $M \times 1$ vector containing the PO data. $\boldsymbol{l}$ projects the 3D displacement in the line of sight (LOS) or along track (AT) in the case of range and azimuth pixel offset respectively. $s=\left[s^{e} s^{n} s^{u}\right]$ is the secular displacement vector (in meters), $t_{i}$ is the time elapsed since the first acquisition. $\tau \tau$ is the total acquisition campaign length. $\boldsymbol{S}_{\boldsymbol{p}}\left(\mathrm{t}_{\zeta}\right)$ and $\boldsymbol{C}_{\boldsymbol{p}}\left(\mathrm{t}_{\zeta}\right)$ are the sinusoidal functions:

$$
\boldsymbol{S}_{p}\left(t_{\xi}\right)=\left[\begin{array}{c}
A_{p}^{e} \sin \left(\omega_{p} t_{\xi}\right) \\
A_{p}^{n} \sin \left(\omega_{p} t_{\xi}\right) \\
A_{p}^{u} \sin \left(\omega_{p} t_{\xi}\right)
\end{array}\right]
$$




$$
\boldsymbol{C}_{p}\left(t_{\xi}\right)=\left[\begin{array}{l}
B_{p}^{e} \cos \left(\omega_{p} t_{\xi}\right) \\
B_{p}^{n} \cos \left(\omega_{p} t_{\xi}\right) \\
B_{p}^{u} \cos \left(\omega_{p} t_{\xi}\right)
\end{array}\right]
$$

Given the model for surface displacements in Eq. 1, we can solve the over determined least-squares problem for each pixel which minimizes the cost function $\Gamma$ :

$$
\Gamma=\|[\boldsymbol{\Psi} \cdot(\boldsymbol{L} \circ \boldsymbol{m})] \cdot \boldsymbol{P}-\boldsymbol{D}\|_{2}^{2}
$$

Where $\boldsymbol{\Psi}$ is an Mx2N matrix containing the $\psi_{i, j}$ values, $\mathrm{m}$ and $\boldsymbol{L}$ are $2 \mathrm{Nx}(6 \mathrm{k}+3)$ matrices and $\boldsymbol{m}$ contains the parameters functions estimated at the acquisition time $t_{\mathrm{i}}$ and $\boldsymbol{L}$ contains the unit vectors $\boldsymbol{l}$ projecting the LOS and AT displacement in the East, North and Up directions. $\mathrm{P}$ is a vector containing the $6 \mathrm{k}+3$ parameters to estimate. The operator ${ }^{\circ}$ represents the Hadamard product while the - operator is the Kronecker product. For further details, we refer the reader to [10]

\section{DATASET AND RESULTS}

We designed CSK observations of RIS to cover nearly the entire ice stream from ascending and descending orbital directions using every available CSK satellite acquired starting August 2013 covering 9 months. From this set of acquisitions, we selected a subset of 21 1-day pairs, 303 -day pairs, 24 4-day and 26 8-day pairs (Fig 1). The magnitude of the displacement requires interferograms with temporal baselines no longer than 8 days and stability of the perpendicular component of the interferometric perpendicular baseline. Examples of PO maps in azimuth and range direction are shown in Fig 2.

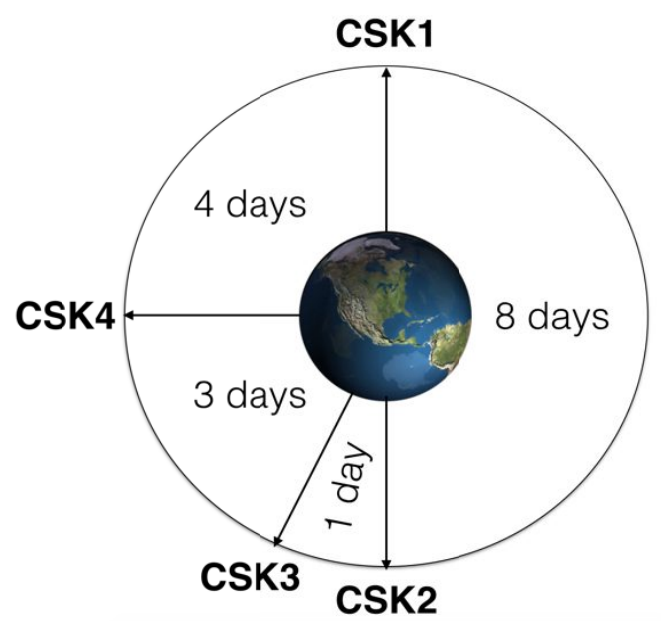

Fig. 1. Relative position of the four satellites in the CSK constellation in the orbital plane and repeat time in interferometric mode (Adapted from [27]). 


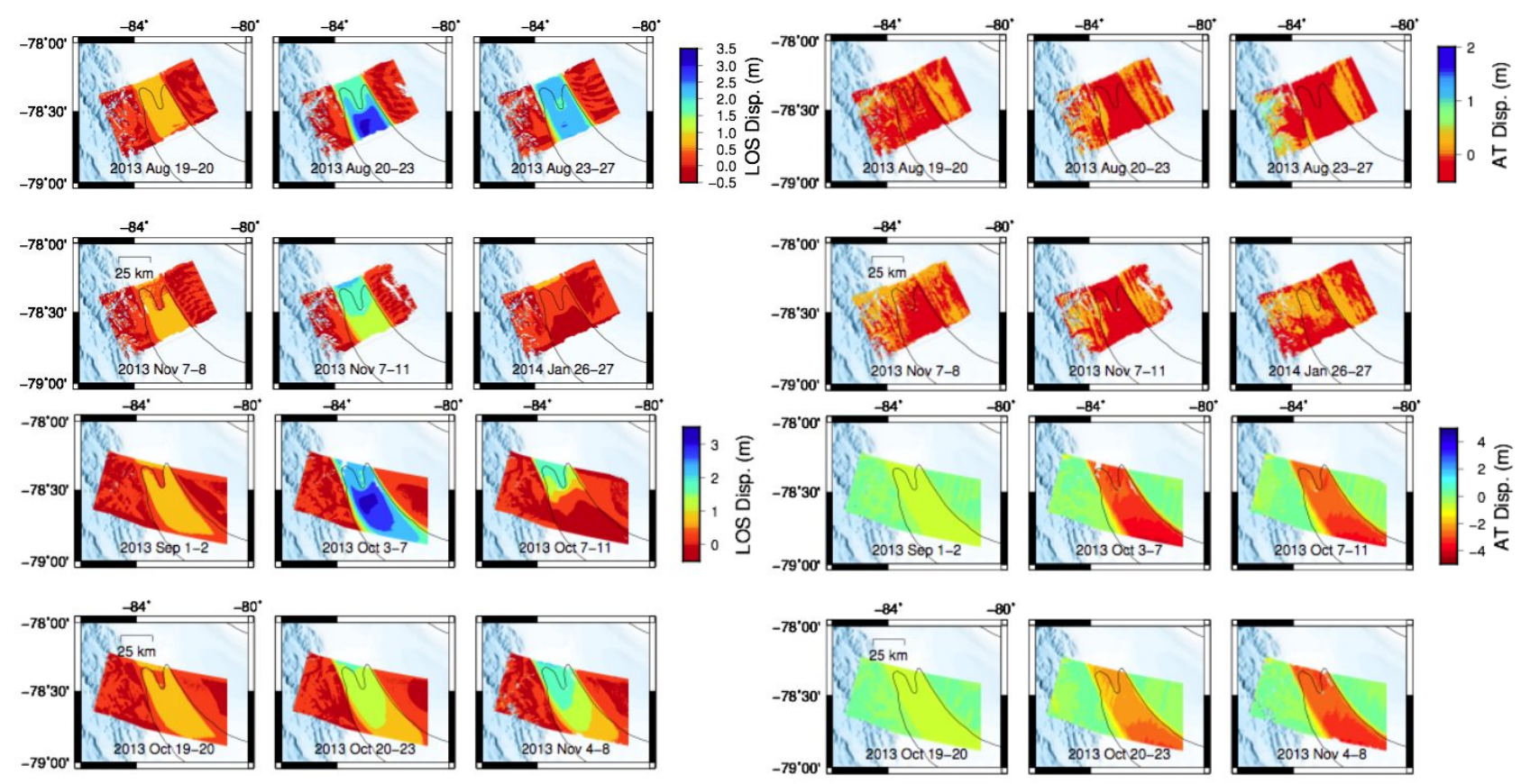

Figure 2: Range (Left), Azimuth (right) pixel offsets formed with scenes acquired on the indicated dates. The southern half of the ice stream in these scenes is floating as part of the Ronne Ice Shelf and the large difference in LOS displacement is due primarily to tidal forcing

Based on our synthetic tests and the CSK acquisition sampling [10] the inverted dictionary of functions is:

$$
\begin{gathered}
\mathrm{d}_{\mathrm{e}}\left(\mathrm{t}_{i}\right)=\mathrm{s}_{\mathrm{e}} \mathrm{t}_{i} / \tau+\mathrm{A}_{\mathrm{MSf}}^{\mathrm{e}} \sin \left(\omega_{\mathrm{Msf}} \mathrm{t}_{i}\right)+\mathrm{B}_{\mathrm{MSf}}^{\mathrm{e}} \cos \left(\omega_{\mathrm{Msf}} \mathrm{t}_{i}\right) \\
\mathrm{d}_{\mathrm{n}}\left(\mathrm{t}_{i}\right)=\mathrm{s}_{\mathrm{n}} \mathrm{t} / \tau+A_{\mathrm{Msf}}^{\mathrm{n}} \sin \left(\omega_{\mathrm{Msf}} \mathrm{t}_{i}\right)+\mathrm{B}_{\mathrm{Msf}}^{\mathrm{n}} \cos \left(\omega_{\mathrm{Msf}} \mathrm{t}_{i}\right) \\
\mathrm{d}_{\mathrm{u}}\left(\mathrm{t}_{i}\right)=\mathrm{s}_{\mathrm{u}} \mathrm{t}_{i} / \tau+\mathrm{B}_{\mathrm{O} 1}^{\mathrm{u}} \cos \left(\omega_{\mathrm{O} 1} \mathrm{t}_{i}\right)+\mathrm{A}_{\mathrm{O} 1}^{\mathrm{u}} \sin \left(\omega_{\mathrm{O} 1} \mathrm{t}_{i}\right)+\mathrm{B}_{\mathrm{M} 2}^{\mathrm{u}} \cos \left(\omega_{\mathrm{M} 2} \mathrm{t}_{i}\right)+\mathrm{A}_{\mathrm{M} 2}^{\mathrm{u}} \sin \left(\omega_{\mathrm{M} 2} \mathrm{t}_{i}\right)
\end{gathered}
$$

Results are showed in Fig. 3. Horizontal (north and east combined components) velocity (Fig 3) in the CSK data varies from $290 \mathrm{~m} / \mathrm{yr}$ upstream to $430 \mathrm{~m} / \mathrm{yr}$ towards the grounding line with a standard deviation varying from $10-20 \%$ of the observed values. Comparison with previously published InSAR mean velocity estimates [15] show good agreement in secular of the horizontal velocity over the central ice stream trunk and a $4.5 \%$ average difference over the shear margins of the ice stream. This difference in the margins can be interpreted as a consequence of the finer resolution of the X-band data compared to the C-band observations and the different resolutions of the final velocity maps. GPS time series that give mean secular and tidal-timescale ice flow along the central trunk of the ice stream. Vertical displacements for O1 (26-hour period) and M2 (12.5-hour period) tidal constituents agree with GPS observations and regional tidal models [35]. Inferred horizontal displacements at the Msf (14.8- day) tidal period agrees with GPS observations collected at multiple locations within the ice stream and over the floating ice shelf [32,35], but show that the phase of the inferred tides is highly sensitive to the geometric dilution of precision and limits the accuracy of the inferred results. 


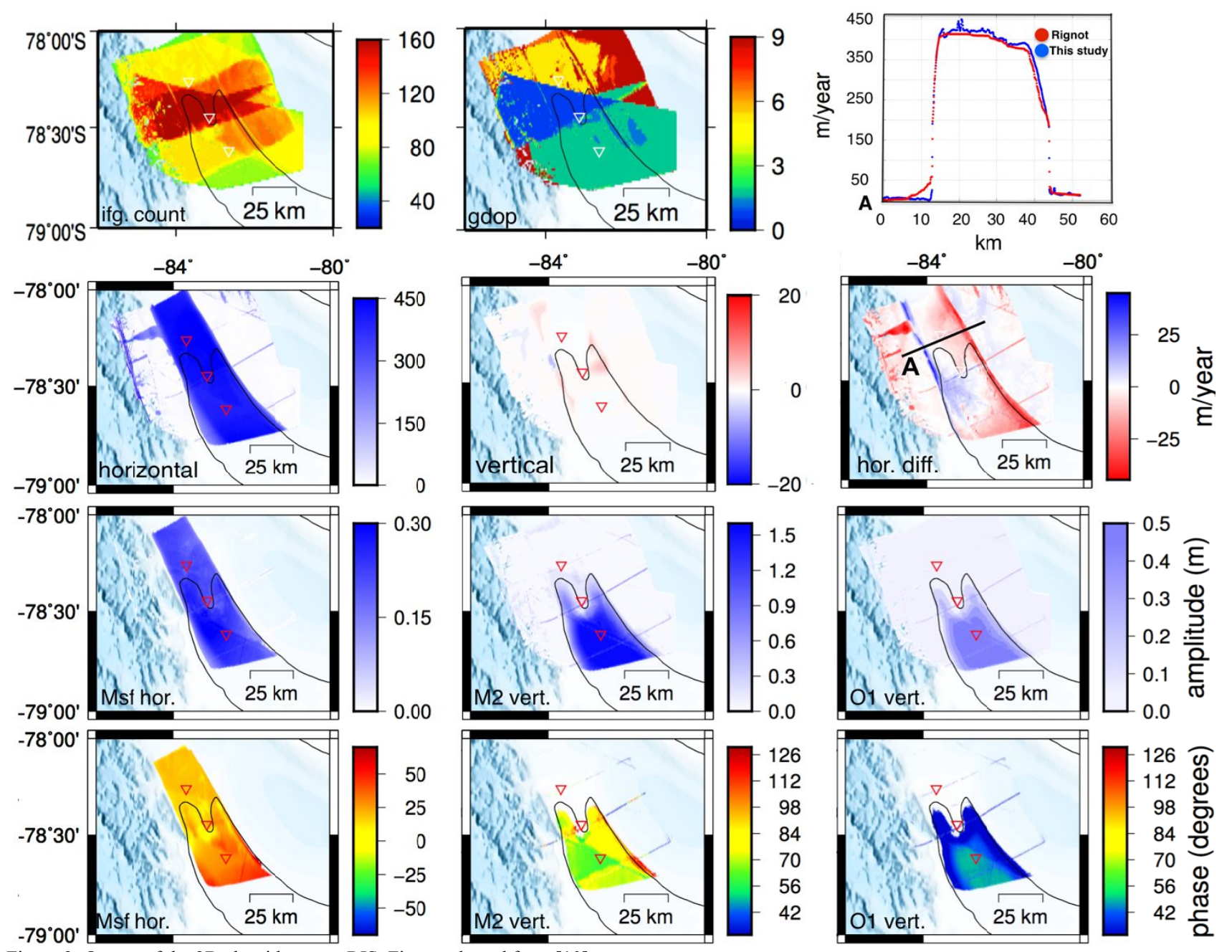

Figure 3: Output of the 3D algorithm over RIS. Figure adapted from [10]

\section{CONCLUSION}

We have described a new method for retrieving 3 dimensional surface deformation fields given a set of pixel offset maps acquired over short time intervals. The RIS example illustrates the power of short repeat times to disentangle secular velocities from tidal effects deforming the ice stream periodically. Given a CSK minimum repeat time of 1 day, we were able to isolate amplitude and phase of the 12.5 hours M2 and 26 hours $\mathrm{O} 1$ vertical tidal components. We also confirm the along-flow upstream modulation of RIS horizontal velocity by the 14.8 day period Msf tide in agreement with GPS observations. This technique, together with the decreasing repeat acquisition intervals in data availability, will help improve our understanding of the evolution of glaciers and large ice masses. 


\section{ACKNOWLEDGEMENTS}

We benefitted from conversations with H. Gudmundsson, P. Lundgren and H. Martens. We used the original COSMOSkyMed product (copyright ASI -Agenzia Spaziale Italiana, 2013-2016). COSMO-SkyMed data products are processed at JPL under license from ASI as part of a collaborative project between CIDOT and JPL/Caltech. We acknowledge the Advanced Rapid Imaging Analysis system (ARIA) for data organization. The The work of P. Milillo was done while he was a visiting student researcher at Caltech and partially sponsored by the National Aeronautics and Space Administration Postdoctoral Program. B. Minchew was partially funded by NASA Cyospheric Sciences award NNX14AH80G, NSF Earth Sciences Postdoctoral Fellowship award 1452587, and donations from the Albert Parvin and ARCS LA Chapter foundations. B. Riel was partially funded by a NASA Earth and Space Sciences fellowship.

\section{REFERENCES}

[1] Goldstein, R. M., Engelhardt, H., Kamb, B., \& Frolich, R. M., " Satellite radar interferometry for monitoring ice sheet motion: application to an Antarctic ice stream," Science 262(5139), 1525-1530 (1993).

[2] Simons, M., Rosen, P. A., [Interferometric synthetic aperture radar geodesy], In Treatise on Geophysics; Editor, G. Schubert.; Elsevier: Amsterdam, 2015; pp. 339-385 (2015).

[3] Ferretti, A., Prati, C., \& Rocca, F.,"Permanent scatterers in SAR interferometry," IEEE Transactions on Geoscience and Remote Sensing 39(1), 8-20 (2001).

[4] Berardino, P., Fornaro, G., Lanari, R., \& Sansosti, E., "A new algorithm for surface deformation monitoring based on small baseline differential SAR interferograms," IEEE Transactions on Geoscience and Remote Sensing 40(11), 2375-2383 (2002).

[5] Milillo, P., Perissin, D., Salzer, J. T., Lundgren, P., Lacava, G., Milillo, G., Serio, C., "Monitoring dam structural health from space: Insights from novel InSAR techniques and multi-parametric modeling applied to the Pertusillo dam Basilicata, Italy," International Journal of Applied Earth Observation and Geoinformation, 52, 221-229, (2016).

[6] Rousset, B., Jolivet, R., Simons, M., Lasserre, C., Riel, B., Milillo, P., Cakir, Z., Renard, F. "An aseismic slip transient on the North Anatolian Fault," Geophysical Research Letters 43(7), 3254-3262 (2016).

[7] Milillo, P., Fielding, E. J., Shulz, W. H., Delbridge, B., \& Burgmann, R., "COSMO-SkyMed spotlight interferometry over rural areas: The Slumgullion landslide in Colorado, USA.” IEEE Journal of Selected Topics in Applied Earth Observations and Remote Sensing 7(7), 2919-2926 (2014).

[8] Riel, B., Milillo, P., Simons, M., Lundgren, P., Kanamori, H., Samsonov, S., "The collapse of Bárðarbunga caldera, Iceland," Geophysical Journal International 202(1), 446-453 (2015).

[9] Milillo, P., Riel, B., Minchew, B., Yun, S. H., Simons, M., Lundgren, P., “On the Synergistic Use of SAR Constellations' Data Exploitation for Earth Science and Natural Hazard Response," IEEE Journal of Selected Topics in Applied Earth Observations and Remote Sensing 9(3), 1095-1100 (2016).

[10] Milillo, P., Minchew, B., Shanker, P., Riel, B., Simons, M., "Geodetic imaging of time dependent 3-component surface deformation: Application to tidal-timescale ice-flow of Rutford Ice Stream, West Antarctica," IEEE Transaction on Geoscience and Remote Sensing, (Submitted) (2016).

[11] Samsonov, S., \& d'Oreye, N., "Multidimensional time-series analysis of ground deformation from multiple InSAR data sets applied to Virunga Volcanic Province," Geophysical Journal International 191(3), 1095-1108 (2012).

[12]Hu, J., Ding, X. L., Li, Z. W., Zhu, J. J., Sun, Q., Zhang, L., \& Omura, M., “A Kalman Filter Based MTInSAR methodology for deriving 3D surface displacement evolutions," Proc. Fringe 2011 697, p.79 (2012).

[13] Joughin, I. R., Kwok, R., \& Fahnestock, M. A., "Interferometric estimation of three-dimensional ice-flow using ascending and descending passes," IEEE Transactions on Geoscience and Remote Sensing 36(1), 25-37 (1998).

[14] Joughin, I., "Ice-sheet velocity mapping: a combined interferometric and speckle-tracking approach," Annals of Glaciology 34(1), 195-201 (2002).

[15]Rignot, E., Mouginot, J., \& Scheuchl, B. "Ice flow of the Antarctic ice sheet," Science 333(6048), 1427-1430 (2011).

[16] Kumar, V., Venkataramana, G., Høgda, K. A., "Glacier surface velocity estimation using SAR interferometry technique applying ascending and descending passes in Himalayas," International Journal of Applied Earth Observation and Geoinformation 13(4), 545-551 (2011).

[17] Gourmelen,N., Kim,S.W., Shepherd,A., Park,J.W., Sundal,A.V., BjÃu"rnsson,H., Palsson,F., "Icevelocity determined using conventional and multiple-aperture InSAR," Earth and Planetary Science Letters 307, 156-160, (2011).

[18] Nagler, T., Rott, H., Hetzenecker, M., Scharrer, K., Magnusson, E., Floricioiu, D., Notarnicola, C., "Retrieval of 3dglacier movement by high resolution x-band sar data," Proc. IGARSS, 3233-3236), (2012). 
[19] Neelmeijer, J., Motagh, M., \& Wetzel, H. U., "Estimating Spatial and Temporal Variability in Surface Kinematics of the Inylchek Glacier, Central Asia, using TerraSAR-X Data," Remote Sensing 6(10), 9239-9259 (2014).

[20] Minchew, B., Simons, M., Hensley, S., Bjornsson, H., Pálsson, F., Milillo, P., "Multiple glacier surges observed with airborne and spaceborne interferometric synthetic aperture radar," Proc. IGARSS, 2015

[21] Minchew, B., Simons, M., Hensley, S., Björnsson, H., \& Pálsson, F., "Early melt season velocity fields of Langjökull and Hofsjökull, central Iceland," Journal of Glaciology 61(226), 253-266 (2015).

[22] Fialko, Y., Sandwell, D., Simons, M., \& Rosen, P., "Three-dimensional deformation caused by the Bam, Iran, earthquake and the origin of shallow slip deficit," Nature 435(7040), 295-299 (2005).

[23] Jung, H. S., Lu, Z., Won, J. S., Poland, M. P., \& Miklius, A., "Mapping three-dimensional surface deformation by combining multiple-aperture interferometry and conventional interferometry: Application to the June 2007 eruption of Kilauea volcano, Hawaii," Geoscience and Remote Sensing Letters IEEE 8(1), 34-38 (2011).

[24] Manconi, A., Casu, F., Ardizzone, F., Bonano, M., Cardinali, M., De Luca, C., Lanari, R. "Brief Communication: Rapid mapping of landslide events: the 3 December 2013 Montescaglioso landslide, Italy," Natural Hazards and Earth System Sciences 14(7), 1835-1841 (2014).

[25] Raspini, F., Ciampalini, A., Del Conte, S., Lombardi, L., Nocentini, M., Gigli, G., Casagli, N., "Exploitation of Amplitude and Phase of Satellite SAR Images for Landslide Mapping: The Case of Montescaglioso (South Italy)," Remote Sensing 7(11), 14576-14596 (2015).

[26] Casu, F., Manconi, A., "Four-dimensional surface evolution of active rifting from spaceborne SAR data," Geosphere, GES01225-1 (2016).

[27]Pepe, A., Solaro, G., and Dema, C., "A minimum curvature combination method for the generation of multiplatform DInSAR deformation time-series,"Proc. Fringe, 2015,

[28] Brunt, K. M., Fricker, H. A., \& Padman, L., "Analysis of ice plains of the Filchner-Ronne Ice Shelf, Antarctica, using ICESat laser altimetry," Journal of Glaciology 57(205), 965-975 (2011).

[29] Sayag, R., \& Worster, M. G., "Elastic dynamics and tidal migration of grounding lines modify subglacial lubrication and melting," Geophysical Research Letters 40(22), 5877-5881 (2013).

[30] Walker, R. T., Parizek, B. R., Alley, R. B., Anandakrishnan, S., Riverman, K. L., Christianson, K., "Ice-shelf tidal flexure and subglacial pressure variations," Earth and Planetary Science Letters 361, 422-428 (2013).

[31] Reeh, N., Christensen, E. L., Mayer, C., \& Olesen, O. B., "Tidal bending of glaciers: a linear viscoelastic approach," Annals of Glaciology 37(1), 83-89 (2003).

[32] Gudmundsson, G. H., "Tides and the flow of Rutford ice stream West Antarctica," Journal of Geophysical Research Earth Surface 112(F4), (2007).

[33] Thompson, J., Simons, M., \& Tsai, V. C., "Modeling the elastic transmission of tidal stresses to great distances inland in channelized ice streams," Cryosphere 8(6), 2007-2029. (2014).

[34] Hetland, E. A., Musé, P., Simons, M., Lin, Y. N., Agram, P. S., DiCaprio, C. J., "Multiscale InSAR time series (MInTS) analysis of surface deformation," Journal of Geophysical Research Solid Earth 117(B2), (2012).

[35] Murray, T., Smith, A. M., King, M. A., \& Weedon, G. P., "Ice flow modulated by tides at up to annual periods at Rutford Ice Stream, West Antarctica," Geophysical Research Letters 34(18), (2007). 